\title{
Numerical Simulation and Experimental Verification of Upsetting Temperature Optimization of Aluminium Alloy
}

\author{
Maros Martinkovic ${ }^{1} \&$ Maria Kapustova ${ }^{1}$ \\ ${ }^{1}$ Slovak University of Technology in Bratislava, Faculty of Materials Science and Technology, J. Bottu 25, 917 \\ 24 Trnava, the Slovak Republic \\ Correspondence: Maros Martinkovic, Slovak University of Technology in Bratislava, Faculty of Materials \\ Science and Technology, J. Bottu 25, 91724 Trnava, the Slovak Republic. Tel: 421-906-068-345. E-mail: \\ maros.martinkovic@stuba.sk
}

Received: February 2, 2012

Accepted: February 15, 2012 Online Published: May 24, 2012

doi:10.5539/mer.v2n1p64

URL: http://dx.doi.org/10.5539/mer.v2n1p64

The research is supported by VEGA Grant No. 1/2594/12 which is supported by Slovak Republic Ministry of Education

\begin{abstract}
Warm forming of metal materials represents a profitable method of precise forming pieces production due to energy and time savings, obtaining of higher surface quality and dimension precision of forming pieces in comparison with hot forming. An optimal forming temperature was selected from experimental measurement of mechanical properties, plasticity and workability of an aluminium alloy. Upsetting forming process of aluminium alloy AlSiMg type was simulated using finite element method at warm forming temperatures. Numerical simulation of the alloy forming based on finite elements methods was verified, the results of the numerical simulation were compared with experimental result - degree of grain boundaries deformation obtained by stereological metallography. From the results an optimal temperature of warm forming was estimated.
\end{abstract}

\section{Introduction}

The warm forming process occurs at temperatures which are above recovery temperatures but below bottom hot forging temperatures. This forming process can obtain higher degree deformation in comparison with cold forming (Skubisz et al., 2006). Warm forming passes with partial strain hardening of metal above recovery temperature and below temperature of recrystallization (Forejt \& Piska, 2006). Energy and time savings at warming up (Forcellese \& Gabrielli, 2000) and higher surface quality and dimension precision of forming pieces after forming in comparison with hot forming are important arguments for investigation of properties of aluminium alloy at warm forming temperatures (Novotny, 2000). Suitability of examined Al alloy for warm bulk forming can be verified by tensile test at higher temperatures - strength limit, characteristics of plasticity for workability at higher temperatures and an exponent of strain hardness are obtained. Numeric simulation can be used to obtain an influence of some factors such as temperature, workpiece material and dimension, friction, forming machine parameters to forming process (Lee \& Jou, 2003). Simulation software enables monitoring of these processes and optimizes parameters of a process at specific conditions (Spisak, 2000). Finite elements methods can lead to excellent results in each place of deformed parts, but it is necessary to verify them (their parameters) by experimental results. The simple way to verify numerical result is to compare them with the experimental result. Bulk forming leads to grain boundary deformation. To obtain value of strain is very simple by stereology - measurement of degree grain boundary orientation which depends on the grain deformation.

\section{Experimental Material}

The subject of plasticity and workability research at warm forming temperatures is aluminium alloy AlSiMg type AW-6063A (6063A). Chemical composition of the alloy is in Table 1. This alloy, which belongs to the group "6000" of aluminium alloys, is determined primarily for hot forming. The alloy was in natural state, without any heat treatment (for instant solution treatment).

Suitability of examined Al alloy for warm bulk forming was verified by tensile test at room and higher temperatures. Cylindrical bar specimens were used for tensile tests. The gage length was $80 \mathrm{~mm}$, diameter $8 \mathrm{~mm}$. 
The specimens were tested at temperatures $20,150,200$ and $250^{\circ} \mathrm{C}$. At each temperature three specimens were tested.

Table 1. Chemical composition of the aluminium alloy

\begin{tabular}{|l|l|l|l|l|l|l|l|}
\hline \multirow{2}{*}{ Elemets } & $\mathrm{Si}$ & $\mathrm{Mg}$ & $\mathrm{Fe}$ & $\mathrm{Cu}$ & $\mathrm{Mn}$ & $\mathrm{Cr}$ & $\mathrm{Al}$ \\
\cline { 2 - 7 } & \multicolumn{7}{|c|}{ wt.\% } \\
\hline $\min$ & 0,45 & 0,4 & & & & & \\
$\max$ & 0,8 & 0,8 & 0,3 & 0,1 & 0,1 & 0,1 & bal \\
\hline
\end{tabular}

Strength limit Rm, characteristics of plasticity for workability at a higher temperature (reduction of area Z, index of plasticity to rupture according to Kolmogorov $\lambda_{R}$, ductility A, Paur's index of plasticity $\mathrm{D}_{\text {sm }}$ ) and exponent of strain hardness $n$ were calculated from measured results on three tested specimens at each tested temperatures. The index of plasticity according to Kolmogorov $\lambda_{R}$ was calculated according equation (1), where $d_{0}$ is an original diameter of test specimen, $\mathrm{d}_{\mathrm{u}}$ is an diameter of specimen in failure place, Paur's index of forming capacity $\mathrm{D}_{\mathrm{sm}}$ was calculated according the equation (2), where $\mathrm{Z}$ is reduction of cross sectional area. Exponent of strain hardness $\mathrm{n}$ was determined as true plastic strain at tensile strength point where plastic deformation stability is lost.

$$
\begin{aligned}
& \lambda_{R}=2 \sqrt{3} \ln \frac{d_{0}}{d_{u}} \\
& D_{s m}=\frac{1}{1-Z}-1
\end{aligned}
$$

Temperature course of tensile strength $\mathrm{R}_{\mathrm{m}}$ is illustrated in Figure 1 and temperature courses of percentage reduction of area $\mathrm{Z}$ and ductility $\mathrm{A}$ are in Figure 2. Temperature courses of index of plasticity according to Kolmogorov $\lambda_{R}$ and Paur's index of forming capacity $D_{s m}$ are in Figure 3. Determined values of strain hardening index at examined temperatures includes Table 2 .

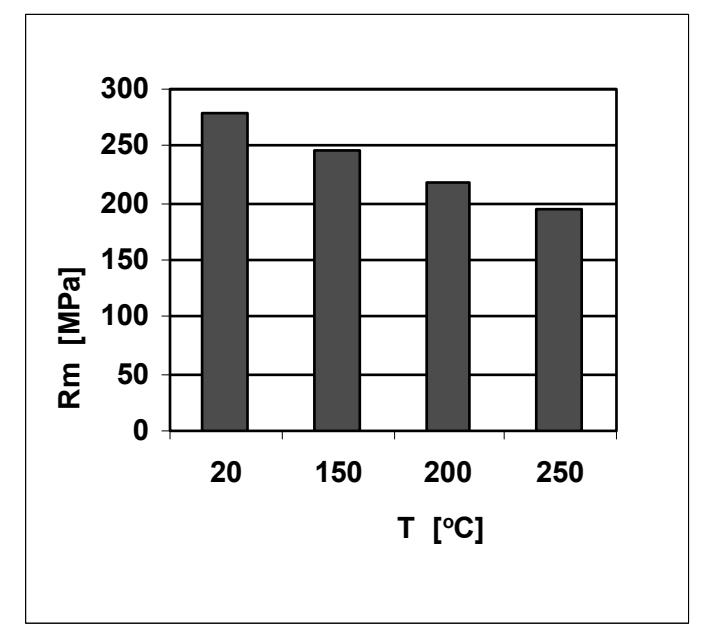

Figure 1. Temperature course of tensile strength $\mathrm{R}_{\mathrm{m}}$ 


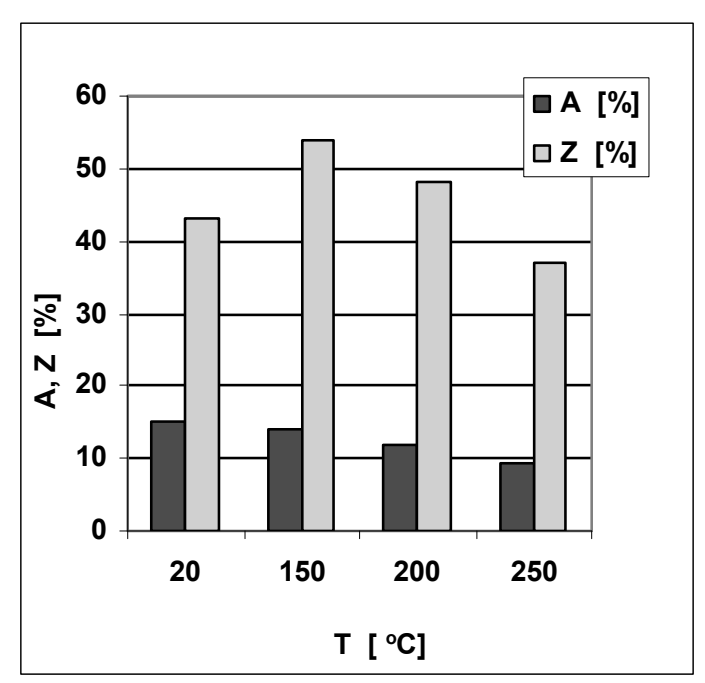

Figure 2. Temperature courses of percentage reduction of area $\mathrm{Z}$ and ductility $\mathrm{A}$

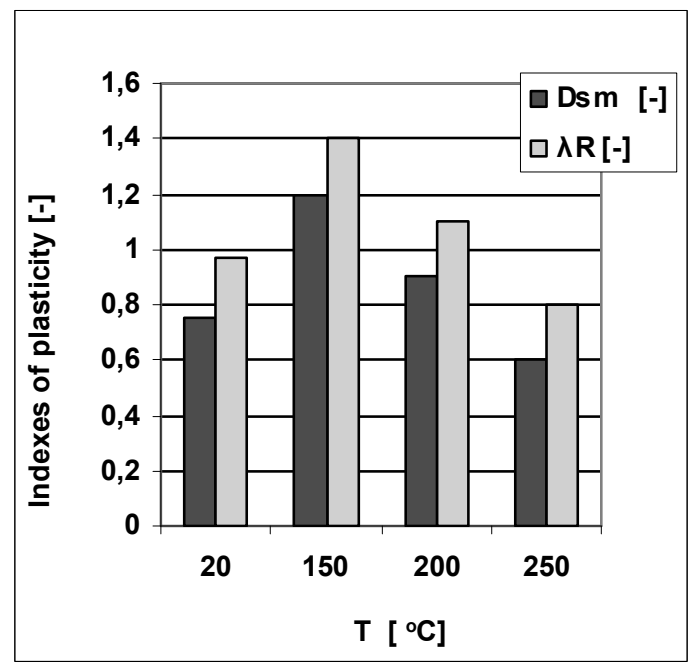

Figure 3. Temperature courses of index of plasticity $\lambda_{R}$ and forming capacity $D_{\text {sm }}$

Table 2. Values of strain hardening index $n$

\begin{tabular}{|l|l|l|l|l|}
\hline $\mathrm{T}\left[{ }^{\circ} \mathrm{C}\right]$ & 20 & 150 & 200 & 250 \\
\hline $\mathrm{n}$ & 0,079 & 0,061 & 0,037 & 0,011 \\
\hline
\end{tabular}

\section{Numerical Simulation}

Numerical simulation of upsetting forming process was exercised to find out material plastic flow at warm forming temperatures. A commercial simulation software MSC SuperForge was used with application of the finite element method. The input parameters for the numeric simulation were: forming in a hydraulic press, tool temperature $100^{\circ} \mathrm{C}$, friction coefficient 0.4 , cylindrical bar (semi-product) from aluminium alloy 6060 with diameter $25 \mathrm{~mm}$ and height $50 \mathrm{~mm}$, warm temperatures 150,200 and $250^{\circ} \mathrm{C}$, semi-product height after deformation $30 \mathrm{~mm}$. The simulation process enabled to observe these results: effective plastic strain, temperature in longitudinal section in the middle of a cylindrical bar and contact pressure. The results are in Figure 4 (corresponding values marked by dots). During deformation at $250^{\circ} \mathrm{C}$ in the middle of the workpiece the 
temperature of the material increased to $270^{\circ} \mathrm{C}$, which exceeds the recrystallization temperature and recrystallization may pass.

\section{Microstructure Analysis}

Warm forming of the real part from the aluminium alloy was executed at the same basic parameters which are described at the numerical simulation. The structure of the aluminium alloy material was observed with about 50x magnification of a light microscope on the metallographic cut of a longitudinal section in the middle of the cylindrical bar. The metallographic cut was mechanical grinded and polished, chemical etched in Keller etcher $\left(1,5 \mathrm{ml} \mathrm{HF}, 3 \mathrm{ml} \mathrm{HNO}, 100 \mathrm{ml} \mathrm{H}_{2} \mathrm{O}\right)$. An example of aluminium alloy structure in basic state is in Figure 5, an example of aluminium alloy structure after deformation is in Figure 6.

The strain of probes on their sections was obtained by stereological measurement of degree grain boundaries deformation - degree of grain boundaries orientation (Martinkovic, 2011). The method of oriented test lines was used (Saltykov, 1970). This method allows very simple and effective experimental estimation of plastic deformation degree by measurement of grain boundary orientation in various places of formed parts even in surface layer deformed for instance by machining (Jurko et al., 2011a; Jurko et al., 2011b). Test lines were placed perpendicular and parallel to the grain boundaries orientation direction affected by straining (Russ \& Dehoff, 2000). From the relative number (number to unit of length) of parallel test lines intersections with grain boundaries $\left(\mathrm{P}_{\mathrm{L}}\right)_{\mathrm{P}}$ and perpendicular lines ones $\left(\mathrm{P}_{\mathrm{L}}\right)_{\mathrm{O}}$ a total relative surface area (area to unit test volume) $\left(\mathrm{S}_{\mathrm{V}}\right)_{\text {Tот }}$ of grains was estimated according the equation (3) and a planar oriented part of relative surface area $\left(\mathrm{S}_{\mathrm{V}}\right)_{\mathrm{OR}}$ of grains was estimated according the equation (4). The relative measure precision was always smaller than $10 \%$ with reliability $90 \%$. Degree of grain boundary orientation was estimated as $\left(\mathrm{S}_{\mathrm{V}}\right)_{\mathrm{OR}}$ to $\left(\mathrm{S}_{\mathrm{V}}\right)_{\mathrm{TOT}}$ ratio.

$$
\begin{aligned}
& \left(\mathrm{S}_{\mathrm{V}}\right)_{\mathrm{TOT}}=\left(\mathrm{P}_{\mathrm{L}}\right)_{\mathrm{O}}+\left(\mathrm{P}_{\mathrm{L}}\right)_{\mathrm{P}} \\
& \left(\mathrm{S}_{\mathrm{V}}\right)_{\mathrm{OR}}=\left(\mathrm{P}_{\mathrm{L}}\right)_{\mathrm{O}}-\left(\mathrm{P}_{\mathrm{L}}\right)_{\mathrm{P}}
\end{aligned}
$$

The results of grain boundary orientation measurement in different places (see Figure 7) of deformed bulk of aluminium alloys specimens are in Table 3.

Table 3. Measured grain boundaries orientation in different places of aluminium alloy specimen

\begin{tabular}{cccc}
\hline Position & & Orientation & {$[\%]$} \\
& 1 & 2 & 3 \\
\hline A & 19 & 27 & 40 \\
B & 18 & 28 & 33 \\
C & 0 & 20 & 32 \\
\hline
\end{tabular}

\section{Discussion}

From the result of mechanical testing at warm temperatures we can see that the best plastic properties of $\mathrm{Al}$ alloy are at $150^{\circ} \mathrm{C}$, on the other hand tensile strength has the maximum value (in the range of warm temperatures). From the values of strain hardening index is evident that area of equilibrium plastic deformation above $200^{\circ} \mathrm{C}$ rapidly decreased. Numerical simulation of upsetting process at warm temperatures 150,200 and $250^{\circ} \mathrm{C}$ showed very good material flow at all temperatures. At $250^{\circ} \mathrm{C}$ during deformation the temperature of the material in the middle of the workpiece increased to $270^{\circ} \mathrm{C}$ (see Figure $4 \mathrm{~b}$ ), which exceeds the recrystallization temperature which was verified by microstructural analysis. The effective strain obtained by numerical simulation of aluminium alloy specimen in the middle of specimen bulk was greater then experimental ones (Table 2). In these places the temperature of the material during deformation increased above the recrystallization temperature $250^{\circ} \mathrm{C}$ and recrystallization passed and the deformation of grain boundaries was decreased. In other places the coincidence of numerical simulation with real state was observed. It suggests that the results of numerical simulation correspond with real states and the computed data are valid. The results showed possibilities of forming of aluminium alloy of group " 6000 " in natural state at warm temperature. The temperature of $200^{\circ} \mathrm{C}$ is recommended for warm forming of AlSiMg alloy. At this temperature lower plasticity, on the other hand lower 
strength and lower contact pressure are present in comparison with $150^{\circ} \mathrm{C}$ (see Figure 4c, d). It can lead to higher lifetime of tool and lower energy consumption.

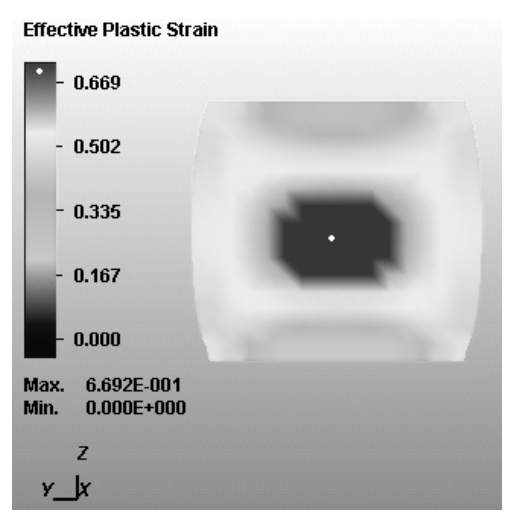

a

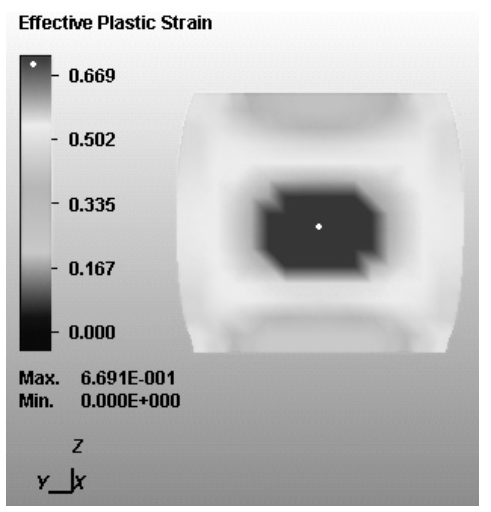

d

\section{Effective Plastic Strain}

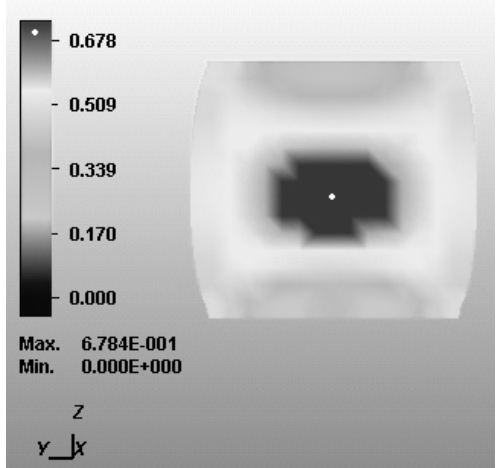

g

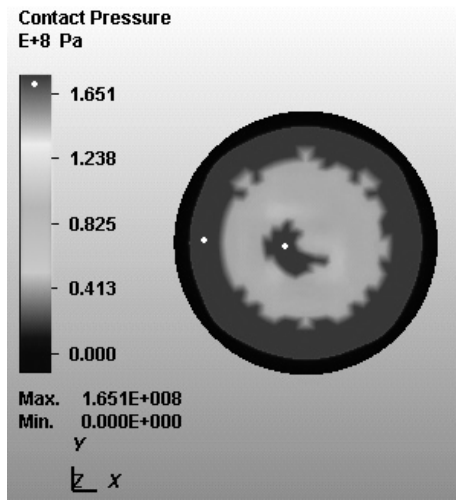

b

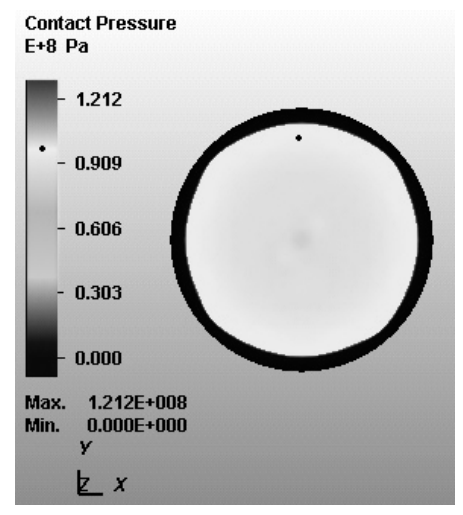

e

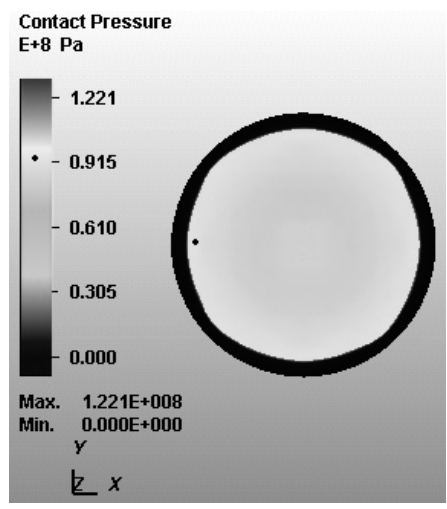

$\mathrm{h}$

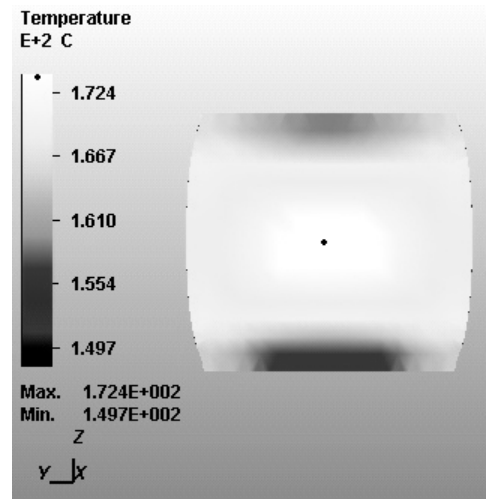

$\mathrm{c}$

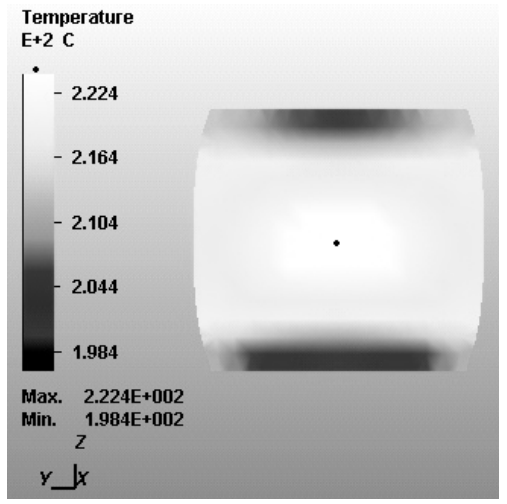

f

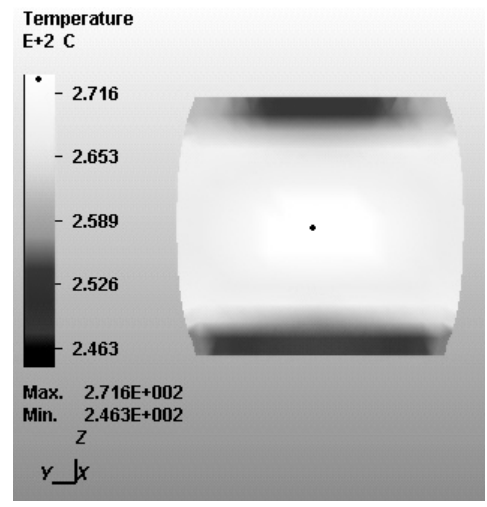

j

Figure 4. Results of upsetting process simulation at $150^{\circ} \mathrm{C}(\mathrm{a}, \mathrm{b}, \mathrm{c}), 200^{\circ} \mathrm{C}(\mathrm{d}, \mathrm{e}, \mathrm{f})$ and $250^{\circ} \mathrm{C}(\mathrm{g}, \mathrm{h}, \mathrm{j})$ 


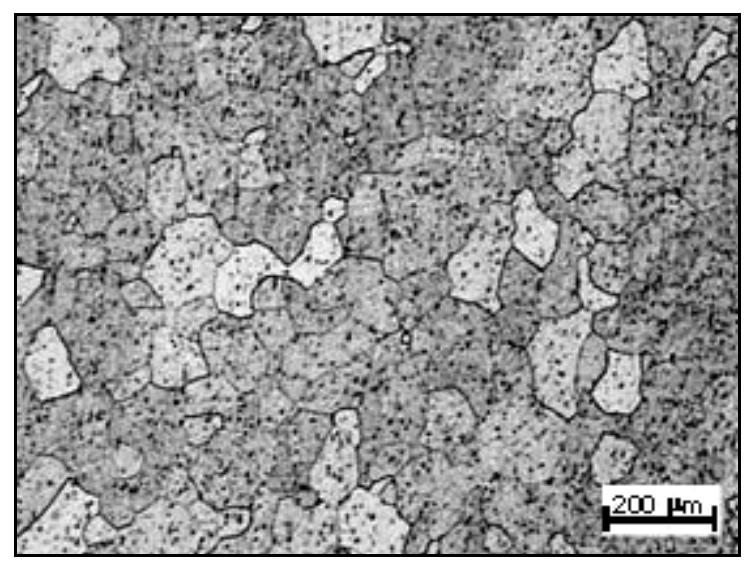

Figure 5. An example of aluminium alloy structure in basic state

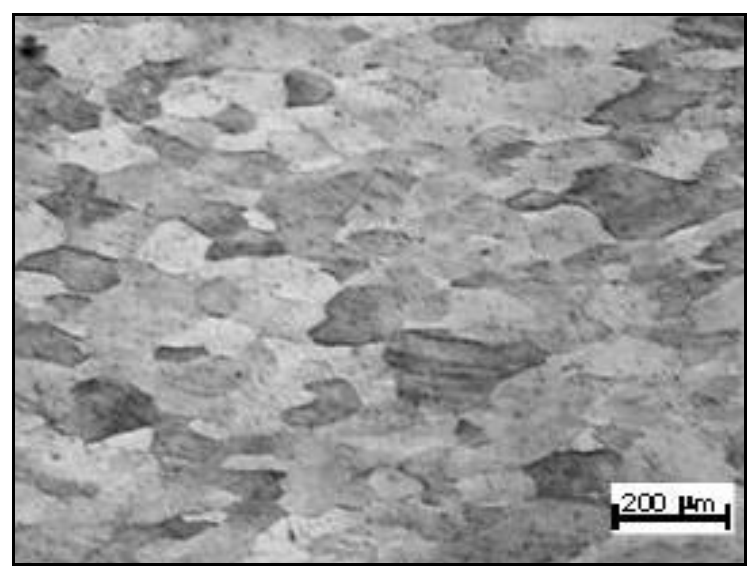

Figure 6. An example of aluminium alloy structure after deformation

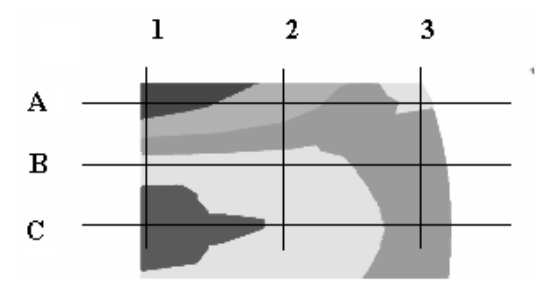

Figure 7. Positions of deformation analysis

\section{Conclusion}

On the basis of mentioned results it is possible to apply the technology of warm forming. The results of the numerical simulation which were experimentally verified confirm that the choice of the temperature $200^{\circ} \mathrm{C}$ at warm forming was correct. Utilization of stereological metallography allows very simple and effective experimental estimation of plastic deformation degree in various places of bulk formed parts and to verify the numerical simulation by comparing these results with numerical simulated ones.

\section{Acknowledgements}

The research is supported by VEGA Grant No. 1/2594/12 which is supported by Slovak Republic Ministry of Education. 


\section{References}

Forcellese, A., \& Gabrielli, F. (2000). Warm forging of aluminium alloys: a new approach for time compression of the forging sequence. International Journal of Machine Tools and Manufacture, 40, 1285-1297. http://dx.doi.org/10.1016/S0890-6955(99)00127-3

Forejt, M., \& Piska, M. (2006). Theory of machining, forming and tools. Brno: CERM.

Jurko, J., Panda, A., Dzupon, M., Pandova, I., \& Gajdos, M. (2011a). Material deformation under the machined surface at drilling holes processing in austenitic stainless steel. Chemical Letters, 105, 600-602.

Jurko, J., Panda, A., \& Gajdos, M. (2011b). Study of changes under the machined surface and accompanying phenomena in the cutting zone during drilling of stainless steels with low carbon content. Metalurgia, METABK, 50(2), 73-144, 113-117.

Lee, R. S., \& Jou, J. L. (2003) Application of numerical simulation for wear analysis of warm forging die. $\begin{array}{lllll}\text { Journal of material processing technology, } & \text { 140, }\end{array}$ http://dx.doi.org/10.1016/S0924-0136(03)00723-4

Martinkovic, M. (2011). Quantitative analysis of material structure. Bratislava: STU.

Novotny, K. (2000). Possibilities of warm forming application. Proceedings of 5th International Conference FORM 2000, September 19- 20th, Brno TU, 211-213.

Pernis, R. (2007). Theory of metal forming. Trencin: TnUAD.

Russ, J. C., \& Dehoff, R. T. (2000). Practical stereology. New York: Plenum Press. http://dx.doi.org/10.1007/978-1-4615-1233-2

Saltykov, S. A. (1970). Stereometric metallography. Moscow: Metallurgy.

Skubisz, P., Sinczak, J., \& Bednarek, S. (2006). Forgeability of Mg-Al-Zn magnesium alloys in hot and warm closed die forging. Journal of Materials Processing Technology, 177, 210-213. http://dx.doi.org/10.1016/j.jmatprotec.2006.04.091 